1 Virchow R. Uber das Epithel der Gallenblase und über einen intermediären Stoffwechsel des Fettes. Virchows Archiv für Pathologische Anatomie und Histologie 1857;11:574-98.

2 Salmenkivi K. Cholesterosis of the gall-bladder: a clinical study based on 269 cholecystectomies. Acta Chir Scand (Suppl) 1964;324:1-93.

3 Mitty WF Jr, Rousselot LM. Cholesterosis of the gallbladder. Gastroenterology 1957;32:910-6.

4 Arnell O. Cholesterolosis vesicae felleae. Acta Chir Scand 1941:85:511-24.

5 Mackay WA. Cholecystitis without stones. Br F Surg 1934;22:274-95.

5 Mackay WA. Cholecystitis without stones. Brf Surg 1934;22:274-95. on 87 cases. Br $\mathcal{F}$ Surg 1937;24:570-94.

7 Dunn FH, Christensen EC, Reynolds J, Jones V, Fordtran JS. Cholecystokinin cholecystography: controlled evaluation in the diagnosis and management of patients with possible acalculous gallbladder disease. FAMA 1974;226:997-1003.

$8 \mathrm{Koga} A$, Todo S, Nishimura $M$. Electron microscopic observations on the cholesterol distributed in the epithelial cells of the gallbladder. Histochemistry 1975;44:303-9.

9 Tilvis RS, Aro J, Strandberg TE, Lempinen M, Miettinen TA. Lipid composition c ile and gallbladder mucosa in patients with alcalculous cholesterolosis. Gastroenterology , ,82;82: 607-15.

10 MacCarty WC. The frequency of strawberry gallbladder. Ann Surg 1919;69:131-9.

11 Tilvis RS, Aro J, Strandberg TE, Lempinen M, Miettinen TA. In vitro synthesis of triglycerides and cholesterol in human gallbladder mucosa. Scand $\mathcal{f}$ Gastroenterol 1982;17:335-40.

$12 \mathrm{Koga}$ A. Fine structure of the human gallbladder with cholesterosis with special reference to the mechanism of lipid accumulation. Brf Exp Pathol 1985;66:605-11.

13 Jacyna MR, Ross PE, Bakar MA, Hopwood D, Bouchier IAD. Characteristics of cholesterol absorption by human gallbladder: relevance to cholesterolosis. $\mathcal{F}$ Clin Pathol 1987;40:524-9.

14 Acalovoschi M, Dumitrascu D, Grigorescu M, Suciu A, Badea G, Paraian I. Pathogenic interrelations between cholesterolosis and cholesterol gallstone disease. Revue Roumaine de Medecine 1983;21:175-9.

15 Lewis KM, Peterson CW. Cholesterolosis of the gallbladder. Observations on 25 cases without stones. Ann Surg 1943;117:450-9.

16 Judd ES, Mentzer SH. Cholesterosis of the gallbladder. Collection of Papers of the Mayo Clinic 1927;19:310-7.

17 Feldman M, Feldman M Jr. Cholesterosis of the gallbladder: an autopsy study of 165 cases. Gastroenterology 1954;27:641-8.

18 Mentzer SH. A clinical and pathological study of cholecystitis and cholesterosis. Surg Gynecol Obstet 1926;42:782-92.

19 Jutras A, Longtin M, Levesque HP. La cholesterolose et ses manifestations radiologiques. Ann Radiol (Paris) 1958;1:179-86.

20 Herbst CA, Mittelstaedt CA, Staab EV, Buckwalter JA. Intraoperative ultrasonography evaluation of the gallbladder in morbidly obese patients. Ann Surg 1984;22:691-2.

21 Cozzolino HJ, Goldstein F, Green RR, Wirts CW. The cystic duct syndrome. fAMA 1963;185:920-4.

22 Nathan MH, Newman A, McFarland J, Murray DJ. Cholecystokinin-cholecystography. Radiology 1969;93:1-8.

23 Goldstein F, Grunt RF, Margulies M. Cholecystokinin-cholecystography in differential diagnosis of acalculous gallbladder disease. Gastroenterology 1972;62:756. [Abstract.]

24 Lennard TWJ, Farndon JR, Taylor RMR. Acalculous biliary pain: diagnosis and selection for cholecystectomy using the cholecystokinin test for pain reproduction. Br $\mathcal{J}$ Surg 1984;71: 368-70.

25 Harvey RF, Read AE. Effect of cholecystokinin on colonic motility and symptoms in patients with the irritable bowel syndrome. Lancet 1973;i:1-3.

26 Burnstein MJ, Vassal KP, Strasberg SM. Results of combined biliary drainage and cholecystokinin cholecystography in 81 patients with normal oral cholecystogram. Ann Surg 1982;196:627-32. 27 Nora PF, Davis RP, Fernandez MJ. Chronic acalculous gallbladder disease: a clinical enigma. World f Surg 1984;8:106-12.

\section{Misleading exercise electrocardiograms}

The referral letter reads: "Thank you for seeing this businessman who went to a fitness assessment unit recently. He was told that he might have heart disease, because his exercise electrocardiogram was abnormal." The cardiologist finds a perfectly healthy man, thinks deeply, and then arranges a coronary arteriogram, which, much to everyone's relief, is normal. This worrying incident affects not only businessmen: more than one senior doctor is the proud possessor of a normal coronary arteriogram.

Exercise testing lacks specificity when applied to men with a low prevalence of coronary artery disease. Nevertheless, we cannot dismiss exercise testing easily because it may have predictive value. Most of the studies have been undertaken in America, although Rumball and Acheson studied 660 healthy men in the Royal Air Force, showing an eightfold increase in the incidence of clinical heart disease (after four to seven years' follow up) in those men with ST segment depression on their exercise electrocardiogram. ${ }^{1}$ The usual criterion of a positive test is $1 \mathrm{~mm}$ or more horizontal depression or down sloping of the ST segment. Froelicher and his colleagues studied exercise tests in 1390 asymptomatic men aged 20-54 in the United States Air Force, following them up for a mean of 6.3 years; $10 \%$ had an abnormal test as judged by the above criterion, and $3 \cdot 3 \%$ of the total went on to develop ischaemic heart disease. ${ }^{2}$ The specificity of the test was $92 \%$, sensitivity $61 \%$, predictive value $10 \%$, and relative risk 14 . These terms have precise meaning, ${ }^{3}$ but the important definition here is predictive value - that is, the percentge of individuals with an abnormal test who have the disease. In 2365 men studied in the Seattle Heart Watch the predictive value of the test was only $5 \% .^{4}$ More recently the Lipid Research Clinic's study of 3600 men followed up for eight years found that $1.8 \%$ men died of coronary disease: $12 \%$ of those with a positive test result compared with $1 \cdot 2 \%$ of those with a negative result, giving a predictive value of $12 \% .^{5}$ Similarly a study of 916 Indiana policemen aged $27-55$ found that $7 \%$ suffered a coronary event: $39 \%$ of those with a positive test result and $5.3 \%$ of those with a negative result - a predictive value of $25 \%$ after $12 \cdot 7$ years follow up. ${ }^{6}$

Hence the subsequent incidence of coronary disease in asymptomatic men is low; exercise testing identifies a group at higher risk but if the predictive value is only $20 \%$ then for every five men tested four will not develop disease in over 12 years of follow up. These figures may be improved by taking into account other risk factors, ${ }^{3}$ as well as the degree of positivity of the test, ${ }^{57}$ but they remain disappointing, as can be predicted by probability analysis. ${ }^{48}$

But do those men with a false positive result go on to develop coronary disease if they are followed up for longer? Our transatlantic colleagues with their relentless efficiency have undertaken coronary arteriography in asymptomatic men with an abnormal electrocardiographic response to exercise testing. Only 34 of 111 aircrewmen studied by Froelicher and his colleagues had appreciable coronary artery disease. ${ }^{9}$ Only two of six Los Angeles firefighters ${ }^{10} 11$ of 30 asymptomatic people studied by Borer and his colleagues, ${ }^{11}$ and one of 10 military officers ${ }^{7}$ had coronary disease despite a positive exercise result. Though small, these numbers suggest that about one third of men with a positive test will have definite coronary disease.

These findings have led to at least two authoritative statements on the medical assessment of airline pilots. "Exercise testing should form no part of routine examination of the trained pilot because of poor reproducibility and specificity and the appreciable number of false positive results." "Effort electrocardiograms should not be employed routinely." In everyday life exercise electrocardiography is even more difficult to justify. Yet some organisations are offering such a service, with the result that some men with tests regarded as positive are now undergoing more elaborate and potentially hazardous investigations to exclude coronary disease. Even if coronary disease is discovered its management is problematical. What should we tell the patient, how should he modify his lifestyle, should he embark on drug treatment, or even should he consider more aggressive treatment? All these questions remain unanswered.

Men who are worried about their health would be best advised to visit their family doctor, and then heed his advice. In my view, the possible expense and anxiety caused by a routine visit to a fitness assessment unit cannot be recommended.

Consultant Cardiologist,

M C PETCH

Papworth Hospital,

Cambridge CB3 8RE

1 Rumball A, Acheson ED. Latent coronary heart disease detected by electrocardiogram before and after exercise. $\mathrm{Br}$ Med f 1963;i:423-8.

2 Froelicher VF, Thomas M, Pillow C, et al. An epidemiological study of asymptomatic men screened with exercise testing for latent coronary heart disease. Am f Cardiol 1975;34:770-6. 
3 Froelicher VF, Morgan D. Exercise testing and ancillary techniques to screen for coronary heart disease. Prog Cardiovasc Dis 1981-2;24:261-74.

4 Bruce RA, DeRouen TA, Hossack KF. Value of maximal exercise tests in risk assessment of primary coronary heart disease events in healthy men. Am f Cardiol 1980;46:371-8.

5 Gordon DJ, Lars-Goran E, Karon JM, et al. Predictive value of the exercise tolerance test for mortality in North American men: the Lipid Research Clinic's mortality follow up study. Circulation 1986;74:252-61.

6 McHenry PL, O'Donnell J, Morris SN, Jordan JJ. The abnormal exercise electrocardiogram in apparently healthy men: a predictor of angina pectoris as an initial coronary event during long term follow up. Circulation 1984;70:547-51.

7 Hollenberg M, Zoltick JM, Go M, et al. Comparison of a quantitative treadmill exercise score with standard electrocardiographic criteria in screening asymptomatic young men for coronary standard electrocardiographic criteria in screen
artery disease. N Engl f Med 1985;313:600-6.

8. Chamberlain DA. Routine and exercise electrocardiography in aircrew; technique, interpretation and recommendations. Eur Heart $f$ 1984;5(suppl A): 55-60.

9 Froelicher VF, Thompson AJ, Wolthuis R, et al. Angiographic findings in asymptomatic aircrewmen with electrocardiographic abnormalities. Am $\mathcal{~ C a r d i o l ~ 1 9 7 7 ; 3 9 : 3 1 - 8 . ~}$

10 Barnard RJ, Gardner GW, Diaco NV. "Ischaemic" heart disease in firefighters with normal coronary arteries. J Occup Med 1976;18:818-20.

11 Borer JS, Brensike JF, Redwood GR, et al. Limitations of the electrocardiographic response to exercise in predicting coronary artery disease. $N$ Engl f Med 1975;293:367-71.

12 Royal College of Physicians of London. The cardiovascular fitness of airline pilots. Br Heart $\mathcal{J}$ 1978;4:335-50.

\section{When things go wrong-again}

Wherever two or more American doctors are gathered together the word malpractice is likely to enter the conversation. Malpractice, and particularly the premiums needed to insure against it, looms large in the American medical consciousness-and no wonder. Malpractice litigation may account for a quarter of the amount spent on doctors' services in America (about $\$ 20$ billion), and it stops doctors delivering babies, "takes the fun out of medicine," and still fails to compensate most of those injured by medical care, even those injured through negligence. ${ }^{1}$ Legislatures in most if not all states are struggling, without much success, to contain the crisis.

We are still a long way from such misery in Britain, but this year's $87 \%$ increase in defence society subscriptions has produced squeals of pain from doctors (p 666). It follows last year's $70 \%$ increase, when we published a leading article arguing not for reform of a legal system manifestly incapable of dealing with this medicosocial problem but rather for a newly minted no fault system. ${ }^{2}$ We have been arguing the case for such a system for years, ${ }^{3}$ and in the past year the BMA has come out in favour of a no fault system, one that would cover medical misadventure rather than all disability.

Now the BMA wants a parliamentary select committee to investigate this problem, a recommendation to be wholeheartedly supported-and not just because doctors' pockets are suffering. Action now may avoid an American style crisis, and a select committee would consider the interests of all groups-patients, doctors, lawyers, and the defence societies. More than anything we need facts, and the select committee would have the power to require people to give evidence. The defence societies might have to release information that would give us more insight into the extent of malpractice. But that still would not tell us how many people are injured by medical care and what happens to thembecause many such people make no complaint. Even after more than a decade of worrying about malpractice the Americans lack the basic data. Dr John Havard quoted last month (15 August, p 399) a statement from an American government committee that the debate on malpractice had "been based more on rhetoric, speculation and misconception, than on factual quantitative data."

We need to avoid such a fate, and a select committee inquiry would help. It would not in itself, however, be enough. We also need a large scale prospective investigation, although urgency may necessitate a retrospective study. The Nuffield Foundation was considering an investigation but seems to have dropped the idea. Perhaps it should think again, and perhaps the defence societies would like to contribute funds - while they still have some to contribute.

Assistant editor, $B M \mathcal{F}$

RICHARD SMITH

1 Mills DH. Medical insurance feasibility study. West $\mathcal{f}$ Med 1978;128:360-5.

2 Smith R. When things go wrong. BrMed f 1986;293:46-2.

3 Anonymous. Compensation: who cares? BrMed $\mathcal{F}$ 1982;284:1428-9.

\section{Acute salpingitis}

Acute salpingitis has become much commoner over the past decade, affecting particularly women aged 15 to $20 .^{1}$ The factors underlying this rise are sexually transmitted diseases, the use of intrauterine contraceptive devices, and infections associated with the termination of pregnancy. The infecting organisms have also changed, with chlamydia now being the commonest: it is implicated in almost two thirds of cases. ${ }^{2-5}$ Gonorrhoea is still an important cause, with the gonococcus isolated in over half the cases. ${ }^{2}$ Other organisms implicated include mycoplasma, ${ }^{2}$ enterobacteria, and anaerobic bacteria. A further factor in the spread of acute salpingitis is carriage of bacteria by spermatozoa to the upper genital tract. ${ }^{6}$

Classically acute salpingitis presents with bilateral ıuwer abdominal pain, fever, and purulent vaginal discharge. The lower abdomen may be tender and even rigid if peritonitis is present, with absent bowel sounds. There may be a purulent, offensive vaginal discharge, which is sometimes blood stained; cervical excitation; and pain and bilateral tenderness of the fornices with enlargement of the adnexae. These findings may be unreliable: Jacobson and Westrom showed that laparoscopy failed to confirm the clinical diagnosis of acute salpingitis in almost a quarter of cases. In cases of doubt or when the condition fails to improve with antibiotic treatment laparoscopic confirmation of the diagnosis may be needed. This may show hyperaemia of the Fallopian tube, oedema, a purulent exudate, and possible evidence of previous tubal disease.

Other investigations include bacteriological culture of high vaginal swabs and cervical swabs, inserted directly into the media. The technique for taking chlamydial swabs must ensure that cells themselves are removed for culture. Estimations of antichlamydial IgG antibody may confirm the presence of chlamydial disease when the results of cultures have been negative, although a raised value does not necessarily indicate active disease. ${ }^{2}$ Swabs may also be taken at laparoscopy, and an endometrial biopsy specimen for cytological studies may confirm the presence of acute salpingitis, although the appearances are not specific for a causative organism. ${ }^{8}$

Severely ill patients need admission to hospital with bed rest, antimicrobial therapy, and analgesia. High vaginal and cervical swabs should be taken and then antibiotic treatment given. As more than one organism is usually responsible for acute salpingitis several antimicrobials are often required, though some (such as doxycycline) should be avoided during pregnancy. A suitable regimen would be spectinomycin 4-6 g six hourly for 24 hours with doxycycline $100 \mathrm{mg}$ twice daily for seven days and daily for a further 14 days, and rectal metronidazole $500 \mathrm{mg}$ twice daily for 10 days. An alternative 